\title{
The impact of cultural industry on economic and em- ployment growth in China
}

\author{
Shiqi Zhou ${ }^{1}$, Songsak Siriboonchitta ${ }^{2}$, WoraphonYamaka ${ }^{3}$, Paravee Maneejuk ${ }^{4}$ \\ 1, 2, 3, 4 Faculty of Economics, Chiang Mai University, Chiangmai, Thailand
}

\section{Keywords \\ Cultural industry \\ Economic growth \\ Employment growth \\ Production function \\ Lasso}

Received: 9 March 2020

Accepted: 19 May 2020

Published: 12 August 2020

\begin{abstract}
The current study explores the impact of cultural industries on economic and employment growth in China using the data from 2004Q1-2018Q4, taking the quarterly data of National culture and related industries value-added, employment, and Gross Domestic Product (GDP) as the main variables. In this study, we choose to work with the production function approach. The simultaneous equations are used to consider the impact of cultural industries on the economy and employment, and the lasso regression is used to screen out the factors that can most affect the economy and employment. The empirical results demonstrate a positive impact of national culture and related industries' value-added on the economic growth and employment growth in China. In the current era, the cultural industry can exert its industrial characteristics, drive the innovation and development of related industries, promote the transformation and upgrading of the industrial structure, and change the mode of economic development. Therefore, studying the factors affecting the development of the cultural industry has important theoretical and practical significance.
\end{abstract}

(C) 2020 The Author(s). Published by TAF Publishing.

\section{INTRODUCTION}

With the continuous strengthening of economic globalization, cultural industries with high efficiency have become a new driving force for economic growth in various countries. And in many developed countries, the cultural industry has already had a considerable scale in economic development, and even the value added of the cultural industry in some countries has surpassed the manufacturing and other industries. As the largest developing country, China is also vigorously developing the cultural industry. As the field with the highest growth potential and innovative vitality in the tertiary industry, culture industry market has maintained a rapid and stable development trend in recent years. It is not only an important part of the national economy, but also a key soft power for national development. With the emphasis on the culture industry, the corresponding policy measures have also been implemented in recent years.

From Chinese perspective, the classification of cultural industries mentioned in this article by the China Statistics Bu- reau belongs to culture-related industries. Changes in the cultural industry can be measured by Value Added of the Country's Cultural and Related Industries. According to the website of the National Bureau of Statistics, after accounting, since 2004, the value added of the country's cultural and related industries has steadily increased, and the proportion of GDP has also increased. The value added of the national culture and related industries in 2018 was 3873.7 billion yuan, accounting for $4.3 \%$ of GDP. In 2018, the of culture and related industries maintained steady and rapid growth, and its proportion in GDP rose steadily. It played a positive role in accelerating the conversion of new and old kinetic energy and promoting high-quality economic development.

With the rapid development of the industry, China's cultural industry employment has shown a trend of continuous increase in total volume and constant adjustment of internal structure. Around 2010, the academic community's overall judgment on the employment level of the cultural industry has changed significantly. After 2000, China's cultural

\footnotetext{
${ }^{*}$ corresponding author: Paravee Maneejuk
}

†email: mparavee@gmail.com 
industry employed population has steadily increased, from 1.472 million in 2000 to 2.351 million in 2018. 2000, 2002, and 2004 were the years with a larger increase. Except for the breakdown of the business industry in 2005 and the decline in the financial crisis in 2009, the development in other years was more balanced. The cultural industry has a large employment capacity.

The cultural industry is an emerging industry with a unique industrial form. Its emergence, development, and growth are all closely related to environmental changes and economic developments at home and abroad. In the current era, the cultural industry can exert its industrial characteristics, drive the innovation and development of related industries, promote the transformation and upgrading of the industrial structure, and change the mode of economic development. New impetus for economic growth. Therefore, studying the factors affecting the development of the cultural industry has important theoretical and practical significance.

\section{LITERATURE REVIEW}

The literature reveals that some empirical studies have focused on investigating the impact of cultural industry on economic growth, concluding that the cultural industry sector is a major contributor to economic growth. Other studies have assessed the impact of the cultural industry sector on economic growth and employment by controlling other determinants of growth, and have indicated that the development of the cultural industry sector is one of the key drivers of the economic growth and employment. Another category of studies aimed to analyze the extent to which there is a causal relationship among cultural industry, economic growth and employment. Regarding the latter, most researchers have concluded that cultural industry is both a cause and a consequence of economic growth and employment.

When it comes to the impact of cultural industries on economic growth, the focus of general scholars' research is to analyze the mechanism between the two. Most of the research points are that the conduction between the two is production efficiency, capital investment and technological innovation. For example, (Solow, 1956) established a neoclassical economic growth model in 1958, explaining the interaction between savings rate, capital accumulation, and economic growth, especially the introduction of technological variables in the model, demonstrating the decisive effect of technological progress on economic growth. With the help of this theory, it can be found that compared with capital, labor, and other factors, cultural industries with rela- tively high technological content are conducive to economic growth. Kibbe (1982) point is that the cultural industry can increase human capital in the development process, and this effect will spill over, and it will have a stronger driving effect on the economy. Padalino and Vivarelli (1997) concluded that cultural industry is one of the fastest growing industries and the value added of culture industry is almost more than $10 \%$ of GDP in developed countries. Culture industry is in the rapid growth stage, and we must take scientific development, increasing innovation through structural reform, technological advances, personnel training and other measures to promote the cultural industry development by leaps. Aoyama (2007) discussed the rise of cultural industries is in part facilitated by the rise of leisure and cultural in the advanced industrialized economies. Cultural industries provide an 'experience', a new and growing source of value in the economy, in commodified and uncommodified forms. Emilia, Vergil, and Monica (2008) found the economy of culture entails both cultural and creative sectors. It has to be noted that, along with the development of the Information and Communication Te chnology (ICT) sector, the contribution of culture to the economy has gradually been acknowledged, in particular with the development of the cultural industries. Gouvea and Vora (2018) discuss implications for governmental-national and local - policy-makers, export promotions policies, their roles in encouraging and nurturing the creative industries, and businesses and artisans themselves. The recognition of the importance of the creative industries is most gratifying. Ochoa and Ramírez (2018) relied on a quantitative co-relational/causal-historical analysis methodology based on information obtained from the Canada and Toronto CMA Industry Profiles to test the hypothesis that cultural industries improve the development of the regional and local economy. Flew (2002) stated that the rise of the knowledge-based economy, and debates about the relationship between information, knowledge and creativity, have provided a stimulus to cultural industries development. Daubaraitè and Startienè (2015) found systematization and evaluation of the sub-sectors defining the impact of cultural industry on national economy. There research provide the basis for targeted funding in order to foster and develop cultural industry impact on national economy.

With China's economic development and industrial structure adjustment and upgrading initially entering a virtuous circle, the great development of the cultural industry has prepared a broad space for the growth of university students' employment needs. The cultural industry needs a large number of college student groups to support de- 
velopment, and college students also prefer the employment field of the cultural industry. Therefore, the development of the cultural industry and the solution of labor employment, especially the absorption of college student groups, can form a positive interaction between the two of them, coexist, merge, derive and promote. With the optimization of China's population knowledge structure, the cultural industry, as an industry category with good development prospects, high knowledge content, and capacity to accommodate a large number of labor, will definitely become a work area suitable for the future development of high-education holders and young people. Therefore, Mr.Lu, Chairman of the Board of Directors of Datang Xishi Group, believes that the cultural industry is known as a "cistern" for absorbing employment, which is an effective way to expand urban employment channels, especially for highly educated talents. Throughout the international economic development, the cultural industry has high knowledge content, wide industrial scope, strong plasticity, low environmental pollution, low energy consumption, high returns, wide employment, large number of people, and can meet people's growing spiritual and cultural life needs And many other advantages, has become one of the fastest growing industries in the world, and is recognized as the most promising industry in the 21st century. Therefore, every country in the world attaches great importance to the development of the cultural industry and supports it as an important strategic industry in the country. Flew (2002) stated that the shift from manufacturing to services as the dominant employment sector has raised important issues about the nature of services sector employment and the services industry model. Ochoa and Ramírez (2018) found these agglomerations represent a significant exchange regarding income and employment; the use and organization of human capital is key factor in reducing the uncertainty of knowledge transfer, multiplying investment returns and fostering innovation in various regions, then it may be conceivable to create tools to consider their contribution to the economy and their influence in other spaces. Xiang (2014) explained that the core of the development of the cultural industry is innovation, and innovation needs to be achieved by technical talents adding their own creativity on the basis of existing cultural resources. Therefore, high-quality, high-tech talents are indispensable in the cultural industry. However, the total number of talents in the cultural and cultural industry is not very ideal, and the distribution of the industrial structure is not reasonable, which directly restricts the development of the cultural industry. While art and culture have been a subject of economic inquiry since the 1960s (Gilang, M., Pradana, Saragih, \& Khairunnisa, 2018; Fields, 1984; Hull, 2009; Taipale, 2015), economic geographers have only recently begun acknowledging the importance of cultural industries as a source of employment in advanced industrialized economies (Currid \& Williams, 2010; Kozak, 2018; Nucharee \& Teeradej, 2019; Pratt, 1997; Power \& Scott, 2004; Scott, 1995). Correa-Quezada et al. (2018) concluded that in the main findings of this research, the analysis of the correspondence of the variables used and the growth show a significant influence of creative employment on regional production and development.

\section{THEORETICAL SETTING}

Due to the main situation that clarify in the beginning of this study, which are the relationship between cultural industry and Economic growth including cultural industry and employment. To make the data more stable, we use the growth rate of each data for calculation. In addition, these two issues have a joint relationship to affect each other in the same period of times. In the models there are more than one equation that have the mutually or jointly dependent or endogenous variables and the simultaneous equation model with a variable specified form as:

$$
\begin{aligned}
& \widehat{\operatorname{rgdp}}_{\mathrm{i}}=\alpha_{0}^{1}+\beta_{1}^{1} \mathrm{rnc}_{\mathrm{i}-1}+\beta_{2}^{1} \widehat{\operatorname{remp}}_{\iota}+\varepsilon_{1} \\
& \widehat{\operatorname{remp}}_{\mathrm{i}}=\alpha_{0}^{2}+\beta_{1}^{2} \mathrm{rnc}_{\mathrm{i}-1}+\beta_{2}^{2} \widehat{\operatorname{rgdp}}_{\iota}+\varepsilon_{2}
\end{aligned}
$$

For a more accurate estimate, we use lasso to screen out the other independent variables to estimate rgdp and remp:

$$
\begin{gathered}
\widehat{\operatorname{rgdp}}_{\mathrm{i}}=f\left(\operatorname{rppl}_{\mathrm{i}-1}, \operatorname{rur}_{\mathrm{i}-1}, \operatorname{rrd}_{\mathrm{i}-1}, \operatorname{rphone}_{\mathrm{i}-1},\right. \\
\left.\operatorname{rtax}_{\mathrm{i}-1} \operatorname{rcemp}_{\mathrm{i}-1}, \operatorname{redu}_{\mathrm{i}-1}, \operatorname{rinc}_{\mathrm{i}-1}, \operatorname{rexp}_{\mathrm{i}-1}, \operatorname{rtour}_{\mathrm{i}-1} \operatorname{rhe~}_{\mathrm{i}-1}, \operatorname{rfin}_{\mathrm{i}-1}, \operatorname{rinv}_{\mathrm{i}-1}, \operatorname{remp}_{i}\right) \\
\widehat{\operatorname{remp}}_{\mathrm{i}}=f\left(\operatorname{rppl}_{\mathrm{i}-1}, \operatorname{rur}_{\mathrm{i}-1}, \operatorname{rrd}_{\mathrm{i}-1}, \operatorname{rphone}_{\mathrm{i}-1}, \operatorname{rtax}_{\mathrm{i}-1},\right. \\
\operatorname{rcemp}_{\mathrm{i}-1}, \operatorname{redu}_{\mathrm{i}-1}, \operatorname{rinc}_{\mathrm{i}-1}, \operatorname{rexp}_{\mathrm{i}-1}, \operatorname{rtour}_{\mathrm{i}-1} \\
\left.\operatorname{rhea}_{\mathrm{i}-1}, \operatorname{rfin}_{\mathrm{i}-1}, \operatorname{rinv}_{\mathrm{i}-1}, \operatorname{rgdp}_{i}\right)
\end{gathered}
$$


Note that, the errors, $\varepsilon_{1}$ and $\varepsilon_{2}$ of each equation are correlated, so that when rgdpi change will cause a change in rempi also when remp ${ }_{i}$ change will be effect in $\operatorname{rgdp}_{i}$ In part of the ${ }_{\alpha}$ and $\beta_{i}$ are structural coefficient and the hypotheses should be made about their sign. We note again that all variable are transformed into growth rate. In this study using the mention variables, because GDP growth rate is quite important indicator and can measure the growth of economy by comparing with another previous years to see the overview of economic. When the economy is expanding, so that the GDP growth rate is positive. But If the GDP growth rate is negative term, which can imply that the economy is in a recession. The method of EMP is same with GDP. This model is estimated by lasso and ridge least square. The best regularized parameter is selected by Bayesian Information Criterion (BIC).

\section{RESEARCH METHODOLOGY}

The paper uses quarterly data in the form of time series data covering 2004Q1 to 2018 Q4 (60 quarters) in China. For this study, all the data are collected from the China National Bureau of Statistics, Comprehensive collation of authors in China.com, China Industry Information Network, Ministry of Culture, China Business Research Institute, Ministry of Industry and Information Technology, World Development Indicators. We use National culture and related industries value added (nc) to represent the development of cultural industries, and GDP (gdp) value and the number of employees (emp) represent economic development and employment respectively. We also used the following macro variables to make our analysis more objective, including: population growth rate (ppl), urbanization rate (ur), research and development expenditure (rd), mobile phone shipments (phone), national tax revenue (tax), total employment in culture (cemp), education expenditure (edu), urban per capita income (inc), urban per capita expenditure (exp), tourism business operating income (tour), urban residents' family health care consumption expenditure (hea), financial expenditure (fin), national planned investment (inv).

This paper uses descriptive statistics and inferential statistics to answer the objectives of this research.

Step one, descriptive statistics are used for explaining the current situation of the cultural industry and economic growth, employment in the case of China such as the mean and correlation.

Step two, finding the relationship between cultural industry and economic growth, employment which follow the main steps: firstly, testing the unit root test to test stationary of time series data which is used in this research by using the Augmented Dickey-Fuller Unit Root Test model. Secondly, after obtaining stationary data from the first step and apply to LASSO Regression for Simultaneous equation model. Hong, Yu, Guo, and Zhao (2014), Liu and Li (2006), Piergiovanni, Carree, and Santarelli (2012), Stam, De Jong, and Marlet (2008), Tribe (2006), Wang (2018) they hold the opinion that cultural industry impacts positively related to GDP. Hong et al. (2014) Piergiovanni et al. (2012), Stam et al. (2008), they hold the opinion that Cultural industry impacts positively related to employment.

\section{RESULTS AND DISCUSSION}

To test the stationarity of the data, we used Augmented Dolado, Gonzalo, and Mayoral (2002) Unit Root Tests to test the first difference unit root test. There are three models we will use which are with constant, with trend and intercept, without trend and intercept. Statistical $p$-value could determine the data is stationary or not, and $p$-value must be less than 5\% significant level, otherwise it will fail to reject of null hypothesis of having a unit root.

From the Table 1 we can conclude that all variables pass the first difference unit root test. All the variables are discovered to be stationary in their without trend and intercept method. We will use growth data to further our study and the variables are now suitable for the follow analysis.

In order to screen out the other independent variables that are significant for economic growth (Equation 3) and employment growth (Equation 4) in our simultaneous equation model, we use lasso to select the best variables to suit the final equations. Because ruc is our main independent variable, we will directly select it without going through this step of screening.

According to the result, we will chose the selected variables into our simultaneous equation model. The model specification. 
TABLE 1. Unit root test results at first difference: At first difference with constant with constant \& trend without constant \& trend

\begin{tabular}{|c|c|c|c|c|c|c|c|c|c|}
\hline & $t$-Statistic & Prob. & & $t$-Statistic & Prob. & & $t$-Statistic & Prob. & \\
\hline $\mathrm{d}(\mathrm{rgdp})$ & -4.8098 & 0.0003 & *** & -4.7686 & 0.0018 & $* * *$ & -4.7366 & 0 & $* * *$ \\
\hline $\mathrm{d}($ remp $)$ & -6.6431 & 0 & $* * *$ & -8.7261 & 0 & $* * *$ & -5.4219 & 0 & $* * *$ \\
\hline $\mathrm{d}(\mathrm{rnc})$ & -7.311 & 0 & $* * *$ & -7.2358 & 0 & $* * *$ & -7.3289 & 0 & $* * *$ \\
\hline$d(\mathrm{rrd})$ & -2.1331 & 0.233 & n0 & -2.1055 & 0.5299 & no & -2.188 & 0.0289 & $* *$ \\
\hline$d$ (rur) & -4.6801 & 0.0004 & $* * *$ & -4.6356 & 0.0027 & $* * *$ & -5.0008 & 0 & $* * *$ \\
\hline $\mathrm{d}(\mathrm{rppl})$ & -9.0261 & 0 & $* * *$ & -9.1859 & 0 & $* * *$ & -8.9975 & 0 & $* * *$ \\
\hline $\mathrm{d}(\mathrm{rtax})$ & -5.108 & 0.0001 & $* * *$ & -5.0707 & 0.0007 & $* * *$ & -4.9958 & 0 & $* * *$ \\
\hline $\mathrm{d}($ rfin $)$ & -3.84 & 0.0047 & $* * *$ & -3.8516 & 0.0218 & $* *$ & -3.7009 & 0.0004 & $* * *$ \\
\hline $\mathrm{d}($ redu $)$ & -4.4665 & 0.0008 & $* * *$ & -4.3414 & 0.0061 & $* * *$ & -4.5589 & 0 & $* * *$ \\
\hline $\mathrm{d}($ rhea $)$ & -4.633 & 0.0004 & $* * *$ & -4.6391 & 0.0026 & $* * *$ & -4.6568 & 0 & $* * *$ \\
\hline $\mathrm{d}$ (rinc) & -3.7115 & 0.0068 & $* * *$ & -3.659 & 0.0348 & $* *$ & -3.7458 & 0.0004 & $* * *$ \\
\hline $\mathrm{d}($ rinv $)$ & -4.0552 & 0.0025 & $* * *$ & -4.0209 & 0.0141 & $* *$ & -3.934 & 0.0002 & $* * *$ \\
\hline$d(\operatorname{rexp})$ & -3.282 & 0.0212 & $* *$ & -3.3225 & 0.0748 & * & -3.5125 & 0.0007 & $* * *$ \\
\hline $\mathrm{d}$ (rphone) & -6.981 & 0 & $* * *$ & -6.9402 & 0 & $* * *$ & -7.0508 & 0 & $* * *$ \\
\hline $\mathrm{d}($ rcemp $)$ & -4.4801 & 0.0007 & $* * *$ & -4.8629 & 0.0012 & $* * *$ & -4.5325 & 0 & $* * *$ \\
\hline $\mathrm{d}$ (rtour) & -5.5583 & 0 & $* * *$ & -5.5315 & 0.0002 & $* * *$ & -5.6135 & 0 & $* * *$ \\
\hline
\end{tabular}

Note: $*, * *, * *$ denote $10 \%, 5 \%$, and $1 \%$ significant level respectively

TABLE 2. lasso variables selection

\begin{tabular}{lll}
\hline \hline & Equation 3 & Equation 4 \\
\hline (Intercept) & 0.0047561882 & -0.0027193616 \\
rgdp & $\cdot$ & 0.05541809 \\
remp & 0.4348342727 & $\cdot$ \\
rphone &. & -0.0007407441 \\
rrd & 0.9904007170 &. \\
rur & -1.8333484115 &. \\
rppl & -0.0437814328 & 0.0242948390 \\
rtax & 0.4178292266 &. \\
rfin & -0.4191259269 &. \\
redu & 0.0626174460 & 0.0029112267 \\
rinv &. & 0.0051625794 \\
rhea & 0.0362724478 & 0.0263613839 \\
rinc & -0.0654986696 &. \\
rexp & -0.0811448835 &. \\
rcemp & 0.2523992706 &. \\
rtour & -0.0767893144 &. \\
\hline \hline
\end{tabular}

Note: “.” denote that this variable will not be selected in the equation

$$
\begin{aligned}
\operatorname{rgdp}=\alpha_{0}^{1} & +\beta_{1}^{1} \text { rnc }+\beta_{2}^{1} \text { remp }+\beta_{3}^{1} \text { rrd }+\beta_{4}^{1} \text { rur } \\
& +\beta_{5}^{1} \text { rppl }+\beta_{6}^{1} \text { rtax }+\beta_{7}^{1} \text { rfin }+\beta_{8}^{1} \text { redu } \\
& +\beta_{9}^{1} \text { rhea }+\beta_{10}^{1} \text { rinc }+\beta_{11}^{1} \text { rexp }+\beta_{12}^{1} \text { rcemp } \\
& +\beta_{13}^{1} \text { rtour }+\varepsilon_{1} \\
\text { remp }=\alpha_{0}^{2}+\beta_{1}^{2} \mathrm{mc}+ & \beta_{2}^{2} \text { rgdp }+\beta_{3}^{2} \text { rphone }+\beta_{4}^{2} \text { rppl } \\
& +\beta_{5}^{2} \text { redu }+\beta_{6}^{2} \text { rinv }+\beta_{7}^{2} \text { rhea }+\varepsilon_{2}
\end{aligned}
$$


In order to find out the relationship between each variable and the economic growth rate and employment change rate, we use the SUR model for regression.
To facilitate understanding and expression, we use GDP to represent the Equation 5, EMP to represent Equation 66, respectively.

TABLE 3. SUR system fit results

\begin{tabular}{lllllll}
\hline \hline & $\boldsymbol{N}$ & $\boldsymbol{D F}$ & SSR & det RCov & OLS- $R^{2}$ & McElroy- $R^{2}$ \\
\hline System & 118 & 96 & 0.001207 & 0 & 0.998141 & 0.996242 \\
\hline \hline
\end{tabular}

TABLE 4. Equation SUR systemfit results

\begin{tabular}{llll}
\hline \hline Equation & DF & SSR & MSE \\
\hline GDP & 45 & 0.001150 & $2.6 \mathrm{e}-05$ \\
EMP & 51 & 0.000058 & $1.0 \mathrm{e}-06$ \\
Equation & RMSE & R2 & Adj R2 \\
GDP & 0.005054 & 0.998230 & 0.997719 \\
EMP & 0.001066 & 0.580583 & 0.523016 \\
\hline \hline
\end{tabular}

TABLE 5. The covariance matrix of the residuals used for estimation

\begin{tabular}{lll}
\hline \hline Equation & GDP & EMP \\
\hline GDP & $2.55408 \mathrm{e}-05$ & $6.61104 \mathrm{e}-08$ \\
EMP & $6.61104 \mathrm{e}-08$ & $1.13632 \mathrm{e}-06$ \\
\hline \hline
\end{tabular}

TABLE 6. The covariance matrix of residuals

\begin{tabular}{lll}
\hline \hline Equation & GDP & EMP \\
\hline GDP & $2.55449 \mathrm{e}-05$ & $1.3275 \mathrm{e}-07$ \\
EMP & $1.3275 \mathrm{e}-07$ & $1.13632 \mathrm{e}-06$ \\
\hline \hline
\end{tabular}

TABLE 7. The correlations of the residuals

\begin{tabular}{lll}
\hline \hline Equation & GDP & EMP \\
\hline GDP & 1.000000 & 0.0245513 \\
EMP & 0.0245513 & 1.000000 \\
\hline \hline
\end{tabular}

TABLE 8. SUR estimates for equation 'GDP'

\begin{tabular}{llllll}
\hline \hline Variable & Estimate & Std. Error & $\boldsymbol{t}$ Value & $\operatorname{Pr}(>|\boldsymbol{t}|)$ & Signif Codes \\
\hline (Intercept) & 0.00365889 & 0.00778220 & 0.47016 & 0.64051038 & \\
rnc & 0.40514908 & 0.09757126 & 4.15234 & 0.00014473 & $* * *$ \\
remp & 3.16394746 & 0.83920546 & 3.77017 & 0.00047303 & $* * *$ \\
rrd & 0.99469594 & 0.00649711 & 153.09823 & $<2.22 \mathrm{e}-16$ & $* * *$ \\
rur & -6.87067223 & 1.45416960 & -4.72481 & $2.2861 \mathrm{e}-05$ & $* * *$ \\
rppl & -0.09263058 & 0.03364506 & -2.75317 & 0.00848156 & $* *$ \\
rtax & 0.52742032 & 0.05575891 & 9.45894 & $2.8837 \mathrm{e}-12$ & $* * *$ \\
rfin & 0.09721807 & 0.14248391 & 0.68231 & 0.49854083 & \\
redu & -0.23023687 & 0.09453594 & -2.43544 & 0.01889904 & $*$ \\
rhea & 0.06233457 & 0.12070260 & 0.5164 & 0.60808211 & \\
rinc & -0.38869186 & 0.11754269 & -3.30681 & 0.00186023 & $* *$ \\
rexp & 0.43852411 & 0.13191972 & 3.32417 & 0.00176986 & $* *$ \\
rcemp & 0.43629222 & 0.05990121 & 7.28353 & $3.8771 \mathrm{e}-09$ & $* * *$ \\
rtour & -0.10704382 & 0.03167811 & -3.37911 & 0.00151058 & $* *$ \\
\hline \hline
\end{tabular}

Note: ${ }^{*}, * * * *$ denote $10 \%, 5 \%$, and $1 \%$ significant level respectively. 
TABLE 9. SUR estimates for equation 'EMP'

\begin{tabular}{llllll}
\hline \hline Variable & Estimate & Std. Error & $\boldsymbol{t}$ Value & $\operatorname{Pr}(>|\boldsymbol{t}|)$ & Signif Codes \\
\hline (Intercept) & $-1.49436 \mathrm{e}-03$ & $5.16722 \mathrm{e}-04$ & -2.89200 & -2.89200 & $* *$ \\
rnc & $9.56921 \mathrm{e}-03$ & $1.01457 \mathrm{e}-02$ & 0.94318 & 0.35003590 & \\
rgdp & $9.29214 \mathrm{e}-05$ & $1.36428 \mathrm{e}-03$ & -0.06811 & 0.94596433 & \\
rphone & $-1.17535 \mathrm{e}-03$ & $5.60446 \mathrm{e}-04$ & -2.09716 & 0.04095604 & $*$ \\
rppl & $2.60339 \mathrm{e}-02$ & $5.38547 \mathrm{e}-03$ & 4.83410 & $1.2695 \mathrm{e}-05$ & $* * *$ \\
redu & $3.67523 \mathrm{e}-03$ & $5.64177 \mathrm{e}-03$ & 0.65143 & 0.51769239 & \\
rinv & $1.25527 \mathrm{e}-02$ & $9.71622 \mathrm{e}-03$ & 1.29193 & 0.20220373 & \\
rhea & $4.34284 \mathrm{e}-02$ & $1.03726 \mathrm{e}-02$ & 4.18684 & 0.00011192 & $* * *$ \\
\hline \hline
\end{tabular}

Note: $*, * *, * * *$ denote $10 \%, 5 \%$, and $1 \%$ significant level respectively.

In Equation (5), the coefficients of RNC is positive and statistically significant, which draw our main conclusion that the growth rate of cultural industry will increase the growth rate of economic. The coefficient of industrial value-added growth rate reached 0.40514908 , indicating that for every one percentage point increase in the added value of the cultural industry, GDP will increase by 0.40514908 percentage points. In terms of other independent variables in equation GDP, the coefficients of the growth rate of employment growth, the growth rate of research and development expenditure, the growth rate of national tax revenue, the growth rate of financial expenditure, the growth rate of total employment in culture are positive which implies that they will increase the growth rate of economic. The coefficient of the growth rate of urbanization rate, population growth rate, the growth rate of education expenditure, the growth rate of urban per capita income are negative which implies that they contribute hardly to the growth of economic in this study.

In Equation (6). The coefficients of rnc is positive but not statistically significant, we can obtain that the growth rate of cultural industry will increase little employment rate as well. The coefficient of industrial value-added growth rate reached $9.56921 \mathrm{e}-03$, indicating that for each percentage point increase in the added value of the cultural industry, EMP will increase by $9.56921 \mathrm{e}-03$ percentage points. In terms of other independent variables in equation EMP, the growth rate of GDP, the coefficients of the growth rate of population, the growth rate of education expenditure, the growth rate of national planned investment and the growth rate of urban residents' family health care consumption expenditure are positive which implies that they will increase the growth rate of employment. The coefficient of the growth rate of mobile phone shipments is negative which implies that they contribute hardly to the growth of employment in this study.

Consequently, the development of the cultural industry has a significant effect on economic growth, but it has a slow ef- fect on employment growth.

\section{CONCLUSION AND IMPLICATIONS}

Present paper investigates the impact of cultural industry on economic growth and employment growth in China employing time series data techniques for the period of 2004 to 2018, taking the quarterly data of National culture and related industries value added, Employment and Gross Domestic Product as the main variables. The LASSO model is utilized in this study to screen other macro independent variables that have an important impact on economic growth and employment growth. The empirical results demonstrate there is a positive impact of National culture and related industries value added on the economic growth and employment growth in China. The difference is that the impact of the cultural industry on the economy is more significant than the impact on employment.

In order to better promote the development of China's cultural industry, firstly, the government should improve the legal system of China's cultural-related industries as soon as possible, accelerate the construction of the legal system, make up for the lack of laws, and provide legal protection for the development of the cultural industry. As an emerging industry, the cultural industry must have an authoritative overall industrial law to regulate and guide. At present, the legal status of the main body of China's cultural market is not clear. The lack of cultural industry investment and financing laws is a key factor restricting the development of cultural industry. Therefore, the focus of the cultural industry legislation is to establish the market position of cultural enterprises through cultural legislation, clarify the formal channels for investment and financing of cultural enterprises, and further attract private capital and foreign investment.

Secondly, the development of cultural industry needs to improve the integration of cultural industry and science and technology. China's investment in science and technology research and development is relatively low, investment 
funds in cultural science and technology research institutions and enterprises are relatively low, and there are not many support policies. It is necessary to further increase investment and formulate more supportive policies to improve the technological level of culture.

Thirdly, promoting the development of the cultural industry requires the improvement of the personnel training sys- tem and incentive mechanism. The essence of competition in the cultural industry is the competition of talents.

Therefore, in order to ensure the development of the cultural industry, there must be a large number of high-quality talents and the establishment of a systematic education and training system for the cultural industry.

\section{REFERENCES}

Aoyama, Y. (2007). The role of consumption and globalization in a cultural industry: The case of flamenco. Geoforum, 38(1), 103-113. doi:https://doi.org/10.1016/j.geoforum.2006.07.004

Correa-Quezada, R., Álvarez-García, J., Río-Rama, D., De la Cruz, M., Maldonado-Erazo, C. P., et al. (2018). Role of creative industries as a regional growth factor. Sustainability, 10(5), 1649-1655. doi:https://doi.org/10.3390/su10051649

Currid, E., \& Williams, S. (2010). The geography of buzz: Art, culture and the social milieu in Los Angeles and New York. Journal of Economic Geography, 10(3), 423-451. doi:https://doi.org/10.1093/jeg/lbp032

Daubaraitè, U., \& Startienè, G. (2015). Creative industries impact on national economy in regard to sub-sectors. ProcediaSocial and Behavioral Sciences, 213, 129-134. doi:https://doi.org/10.1016/j.sbspro.2015.11.415

Dolado, J. J., Gonzalo, J., \& Mayoral, L. (2002). A fractional dickey- fuller test for unit roots. Econometrica, 70(5), 1963-2006. doi:https://doi.org/10.1111/1468-0262.00359

Emilia, T., Vergil, V., \& Monica, T. (2008). The impact of cultural-creative industries on the economic growth-a quantitative approach. Annals of the University of Oradea, Economic Science Series, 17(2), 56-70.

Fields, G. S. (1984). Employment, income distribution and economic growth in seven small open economies. The Economic Journal, 94(373), 74-83. doi:https://doi.org/10.2307/2232216

Flew, T. (2002). Beyond ad hocery: Defining creative industries. In Cultural Sites, Cultural Theory, Cultural Policy, The Second International Conference on Cultural Policy Research, California, CA.

Gilang, A., M., F., Pradana, M., Saragih, R., \& Khairunnisa, R. (2018). Good corporate governance towards employee performance at Indonesian energy company. International Journal of Business and Economic Affairs, 3(2), 48-56. doi:https://doi.org/10.24088/ijbea-2018-32001

Gouvea, R., \& Vora, G. (2018). Creative industries and economic growth: Stability of creative products exports earnings. Creative Industries Journal, 11(1), 22-53. doi:https://doi.org/10.1080/17510694.2017.1416529

Hong, J., Yu, W., Guo, X., \& Zhao, D. (2014). Creative industries agglomeration, regional innovation and productivity growth in China. Chinese Geographical Science, 24(2), 258-268. doi:https://doi.org/10.1007/s11769-013-0617-6

Hull, K. (2009). Understanding the relationship between economic growth, employment and poverty reduction. Havard Review, 5(8), 30-50.

Kibbe, B. (1982). Cultural industries: A challenge for the future of culture. Retrieved from https://bit. Iy/3aKFq0v

Kozak, M. (2018). Conceptualizing employer branding: Is the whole more than the sum of its parts? Case study-based evidence from Thailand. International Journal of Business and Administrative Studies, 4(5), 197-207. doi:https:// dx.doi.org/10.20469/ijbas.4.10002-5

Liu, X., \& Li, G. (2006). Empirical research on comprehensive evaluation system based on sustainable development the case of Xi'an City. Modern Economic Sciences, 28(3), 96-103.

Nucharee, S., \& Teeradej, P. (2019). Roles of expectancy on employee engagement and job performance. Journal of Administrative and Business Studies, 5(2), 88-98. doi:https://doi.org/10.20474/jabs-5.2.3

Ochoa, E. A., \& Ramírez, P. M. C. (2018). Cultural industries and spatial economic growth a model for the emergence of the creative cluster in the architecture of Toronto. City, Culture and Society, 14, 47-55. doi:https://doi.org/10.1016/ j.ccs.2018.03.001

Padalino, S., \& Vivarelli, M. (1997). The employment intensity of economic growth in the G-7 countries. International Labour Review, 136, 191-200.

Piergiovanni, R., Carree, M. A., \& Santarelli, E. (2012). Creative industries, new business formation, and regional economic growth. Small Business Economics, 39(3), 539-560. doi:https://doi.org/10.1007/s11187-011-9329-4 
Power, D., \& Scott, A. J. (2004). Cultural industries and the production of culture. London, UK: Routledge.

Pratt, A. C. (1997). The cultural industries production system: A case study of employment change in Britain, 1984-91. Environment and Planning A, 29(11), 1953-1974. doi:https://doi.org/10.1068/a291953

Scott, P. (1995). The meanings of mass higher education. London, UK: McGraw-Hill Education.

Solow, R. M. (1956). A contribution to the theory of economic growth. The Quarterly Journal of Economics, 70(1), 65-94. doi:https://doi.org/10.2307/1884513

Stam, E., De Jong, J. P., \& Marlet, G. (2008). Creative industries in the Netherlands: Structure, development, innovativeness and effects on urban growth. Geografiska Annaler: Series B, Human Geography, 90(2), 119-132. doi:https://doi.org/ 10.1111/j.1468-0467.2008.00282.x

Taipale, S. (2015). Theorizing cultural work: Labour, continuity and change in the cultural and creative industries. New York, NY: Taylor \& Francis.

Tribe, J. (2006). The truth about tourism. Annals of Tourism Research, 33(2), 360-381. doi:https://doi.org/10.1016/ j.annals.2005.11.001

Wang, Y. (2018). Research on the evaluation, structure and efficiency of china's leisure industry development. Retrieved from https://bit.1y/3iSa3nu

Xiang, H. Y. (2014). Introduction: 2011-2015: Principles of national cultural strategy and cultural industries development. In, China cultural and creative industries reports 2013. Berlin, Germany: Springer. 